\title{
SEPTAL INFARCTION WITH RECOVERY OF THE ELECTROCARDIOGRAM
}

\author{
BY \\ D. GORDON ABRAHAMS* \\ From the Medical Unit, the London Hospital \\ Received May 11, 1956
}

The different electrocardiographic patterns that are associated with infarction of various parts of the heart are widely recognized today. This knowledge has been acquired from numerous studies correlating the electrocardiograms recorded during life with the position of the pathological changes found in the heart at necropsy. In general the management and prognosis of cardiac infarction depends upon the extent of the damage sustained by the heart; the anatomical site of infarction seems to be relatively unimportant in this respect. The description of yet another " type " of cardiac infarction would therefore appear to be of little practical importance.

Recently, however, several patients have been observed in whom unusual electrocardiographic features were associated with the infarction of a particular part of the heart-namely the interventricular septum. The clinical features of these patients were also rather unusual in certain respects. Five such patients are described in this paper; in each instance chest pain was accompanied by an abnormal electrocardiogram, so that a diagnosis of cardiac infarction was made. All the electrocardiograms showed a consistent and distinctive pattern; the initial abnormalities were similar, and the subsequent behaviour was surprising, for all reverted to normal leaving no trace of the previous infarction. Two of the patients died later, and post-mortem examinations were made. From an analysis of the case histories, clinical findings, electrocardiograms, and the available evidence at necropsy, certain facts have emerged that seem worth recording.

\section{Clinical Features}

It is not proposed to discuss the clinical features of the individual cases in detail but a summary of the relevant facts is provided in Table $I$.

There was nothing to suggest a common familial tendency towards heart disease in the members of the group. There were four men and one woman in the series-a distribution that reflects the usual sex incidence of cardiac infarction. Their ages, when first seen, ranged from sixty-six to forty-seven years with an average of just under fifty-five years. High blood pressure was not a prominent finding, for only one patient (Case 3) had persistent hypertension, and one other (Case 1) transient hypertension of short duration. In only one (Case 3) was heart disease recognizable by clinical methods.

All members of the series had pain in the chest at one time or another. In two patients this was typical cardiac pain, but in the others the pain was atypical, and in these three the electrocardiographic findings were unexpected. It is also worthy of note that none of the patients has suffered subsequent attacks of angina pectoris during the period of follow-up.

A most interesting and prominent feature was the frequency of associated gastro-intestinal disease and symptoms. Thus one man (Case 2) was a life-long dyspeptic, and suffered a perforated ulcer about eighteen months before his first attendance. In another man gastrectomy had to be

* Now Senior Lecturer, Dept. of Medicine, University College, Ibadan, Nigeria. 
performed for intractable peptic ulceration (Case 5). Cholecystectomy was necessary in a third for recurrent gall-bladder colic (Case 3). A fourth (Case 1) suffered from minor attacks of indigestion for which no cause could be found, and only one (Case 4) was free from digestive symptoms. The presence of demonstrable disease in the gastro-intestinal tract, occurring as it did in the majority of the patients, complicated the clinical picture and rendered an accurate clinical diagnosis extremely difficult in some instances.

The chest pain was accompanied by signs of circulatory disturbance in only one patient-an elderly woman who had recently undergone cholecystectomy (Case 3). None of the others showed any signs of cardiac insufficiency, and the majority did not even seem to take their pain very seriously.

Two patients (Cases 4 and 5) died after three and twenty-two months observation respectively. The three survivors have been watched for periods of from twenty to forty-four months; all are enjoying a normal, unrestricted life. No patient has had a recurrence of symptoms and their electrocardiograms have remained normal.

TABLE I

Clinical Features of Five Patients in Septal Infarction

\begin{tabular}{|c|c|c|c|c|c|c|c|c|}
\hline $\begin{array}{l}\text { Case } \\
\text { No. }\end{array}$ & Sex & Age* & $\begin{array}{l}\text { Chest } \\
\text { pain } †\end{array}$ & $\begin{array}{c}\text { Signs of } \\
\text { heart disease }\end{array}$ & B.P. & Associated disease & $\begin{array}{l}\text { Period of } \\
\text { observation }\end{array}$ & $\begin{array}{l}\text { Present } \\
\text { status }\end{array}$ \\
\hline 1 & $\mathbf{M}$ & 47 & Atypical & Absent & $\begin{array}{l}170 / 120 \\
140 / 80\end{array}$ & $\begin{array}{l}\text { Acute nephritis. } \\
\text { "Minor" dyspepsia }\end{array}$ & 44 months & Symptom free \\
\hline 2 & $\mathbf{M}$ & 56 & Atypical & Absent & $140 / 80$ & $\begin{array}{l}\text { Major dyspepsia. Perfor- } \\
\text { ated duodenal ulcer } \\
1952\end{array}$ & 22 months & Symptom free \\
\hline 3 & $F$ & 66 & Typical & Present & $235 / 160$ & $\begin{array}{l}\text { Gall-stones. Cholecyst- } \\
\text { ectomy. Hypertensive } \\
\text { heart disease }\end{array}$ & 26 months & $\begin{array}{l}\text { Well on hypoten- } \\
\text { sive therapy }\end{array}$ \\
\hline 4 & $\bar{M}$ & 55 & Atypical & Absent & $155 / 95$ & $\begin{array}{l}\text { Venous thrombosis in the } \\
\text { legs }\end{array}$ & 3 months & Dead \\
\hline 5 & $\mathbf{M}$ & 50 & Typical & Absent & $130 / 80$ & 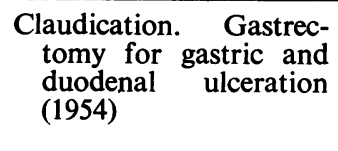 & 22 months & Dead \\
\hline
\end{tabular}

* Age when patient first came under observation.

$\dagger$ Classified according to criteria for cardiac pain based on the site of the pain, its duration, character, relation to exertion, and relief by rest.

\section{ELECTROCARDIOGRAMS}

The electrocardiograms of all patients were remarkably similar during the period when abnormalities were observed, and presented three distinctive features. Pathological Q waves were never present, the $\mathrm{S}-\mathrm{T}$ segment was always iso-electric, and all abnormalities were confined to $\mathrm{T}$ wave changes. The most important characteristic was the complete return to normal subsequently. Similar electrocardiograms were reported by East and Oram (1948) and by Evans (1955), and these authors attributed the transient changes to myocardial ischæmia from coronary artery spasm.

The $T$ wave changes were most apparent in the chest leads-in fact T wave inversion in CR4 was invariable. From this position, which is over the interventricular septum and roughly about the middle of the heart, the $T$ wave inversion extended either to the right involving CR1, or to the left so that CR7 was affected. In one patient (Case 2) the T wave was diphasic in both CR 1 and CR7 so that the cardiac damage was evidently more extensive. T wave inversion in the standard limb leads usually accompanied these changes in the præcordial leads, but sometimes the distribution of changes in the limb leads was surprising. Thus, although the præcordial leads always suggested that the 
anterior surface of the heart was affected, on one occasion (Fig. 3) the limb leads suggested that the lesion was posterior. A possible explanation lies in the distribution of the coronary arteries that supply the septum.

The distribution of $\mathrm{T}$ wave changes in these patients is summarized in Table II and a typical tracing is illustrated in Fig. 1.

TABLE II

Abnormalities of T Waves in Electrocardiograms of Five Patients with Septal Infarction

\begin{tabular}{|c|c|c|c|c|c|c|}
\hline \multirow{2}{*}{ Case } & \multicolumn{3}{|c|}{ Standard leads } & \multicolumn{3}{|c|}{ Præcordial leads } \\
\hline & I & II & III & CR1 & CR4 & CR7 \\
\hline 1 & $T_{\downarrow}$ & $T_{\downarrow}$ & & & $T_{\downarrow}$ & $T_{\downarrow}$ \\
\hline 2 & $\mathbf{T}_{\downarrow}$ & & & $\underset{T}{\text { Diphasic }}$ & $T_{\downarrow}$ & $\underset{T}{\text { Diphasic }}$ \\
\hline 3 & $T_{\downarrow}$ & $T \downarrow$ & & & $T_{\downarrow}$ & $T_{\downarrow}$ \\
\hline 4 & & $T \downarrow$ & $T_{\downarrow}$ & $T_{\downarrow}$ & $T_{\downarrow}$ & \\
\hline 5 & & & & $\underset{T}{\text { Diphasic }}$ & $T_{\downarrow}$ & \\
\hline
\end{tabular}

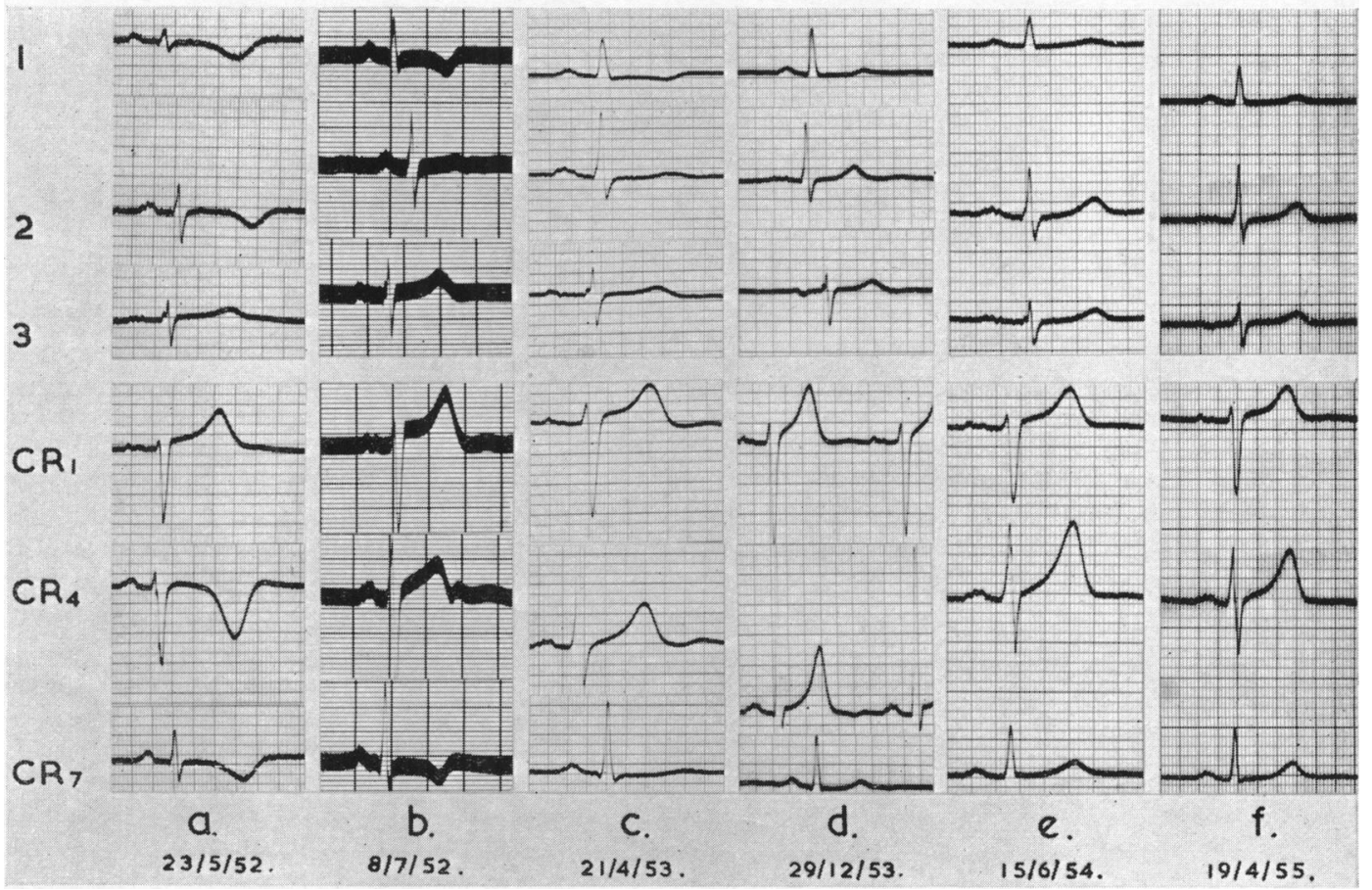

FIG. 1.-Case 1. (a). T wave inversion in I, II, CR4 and CR7 with iso-electric S-T segments. (b). T wave inversion in I and CR7 only with flat T2; the S-T segment shows $1 \mathrm{~mm}$. depression in I and CR7 ascribed to hypertension. (c), (d), (e) and (f). Stages in subsequent restitution of the graph. 
The duration of the electrocardiographic changes varied considerably, as did the length of time necessary for complete recovery to occur. Fig. 1 shows $\mathrm{T}$ wave inversion persisting in CR7 for five weeks, and in lead I for at least a year before a change in direction occurred. In Fig. 2 there was a three-week interval between the recording of $a$ and $c$, but these tracings are almost identical and no improvement is evident. Unless daily tracings are taken it is impossible to determine when improvement begins, and such an undertaking is frequently impracticable. It seems, however, that once improvement begins, it proceeds quickly and is unaffected by the length of time during which the tracing has remained abnormal. This rapid recovery, once initiated, is well illustrated by Case 5 . Electrocardiograms taken on April 29 and May 14, 1953, are reproduced in Fig. 2. They are

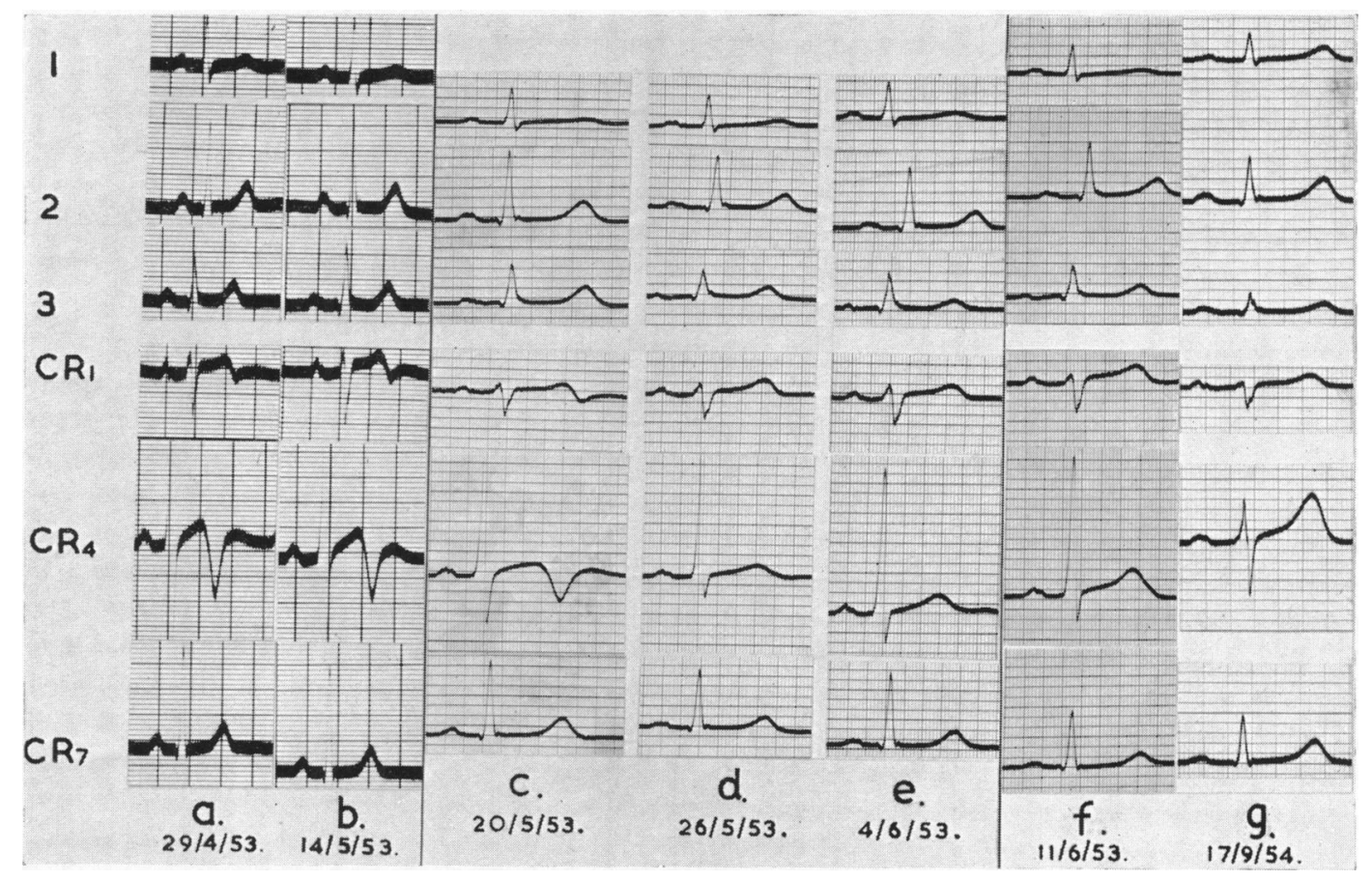

FIG. 2.-Case 5. (a), (b) and (c). Identical abnormailty in the T wave in CR1 and CR4. (d). Considerable improvement after one week in hospital, and further recovery is shown in (e) which is considered a normal tracing. This illustrates the rapid change in the direction of the T wave in CR1 and CR4 once recovery has been initiated.

identical, revealing gross $\mathrm{T}$ wave changes in CR1 and CR4. The patient was then admitted to hospital and the subsequent behaviour of the electrocardiogram is shown. On May 20 the T wave inversion was unchanged, yet six days later a remarkable improvement had taken place. Further improvement in the T wave in lead I and CR4 was evident over the next two weeks (Fig. 2 e and f).

It is extremely difficult to judge when complete reversion to the normal tracing has occurred, or when further improvement can be anticipated. Once an inverted $T$ wave has become upright, an increase in its height is the sole indication that further recovery of the electrocardiogram has taken place. Opinions as to what constitutes a normal electrocardiogram in any individual vary widely, and argument has particularly centred around the height of the T wave in certain leads. Quite apart from any differences in the standardization of the tracings, this segment is peculiarly susceptible to changes in heart rate, posture, and body build and, in the case of the præcordial electrocardiogram, minor alterations in the position of the exploring electrode may exert a considerable influence. It is not therefore surprising that in the present series of patients, apparent improvement in the 
electrocardiogram was sometimes observed even after it had been considered to have returned to normal. This particular point is well shown in Fig. 1.

In summary, it may be said that these electrocardiograms show a consistent pattern. Experience shows that when this pattern is seen, considerable and probably complete recovery of the electrocardiogram may be confidently predicted. The gross changes may persist for weeks without any prejudice to future recovery. When this recovery does begin, it may be very rapid to start with, remarkable improvement occurring within the space of a few days. Subsequent progress is usually slower and minor blemishes may evidently persist for months or even years.

The significance of this electrocardiographic pattern, in terms of underlying cardiac disease, is best discussed with the post-mortem findings.

\section{MORBID ANATOMY}

Of the two patients who died, one (Case 4) had been observed for three months. His electrocardiograms are reproduced in Fig. 3; shortly after the last tracing in the series was taken he was admitted to another hospital where he died two weeks later. An electrocardiogram was recorded five days before he died; this is not illustrated here, but showed no change from Fig. 3d.

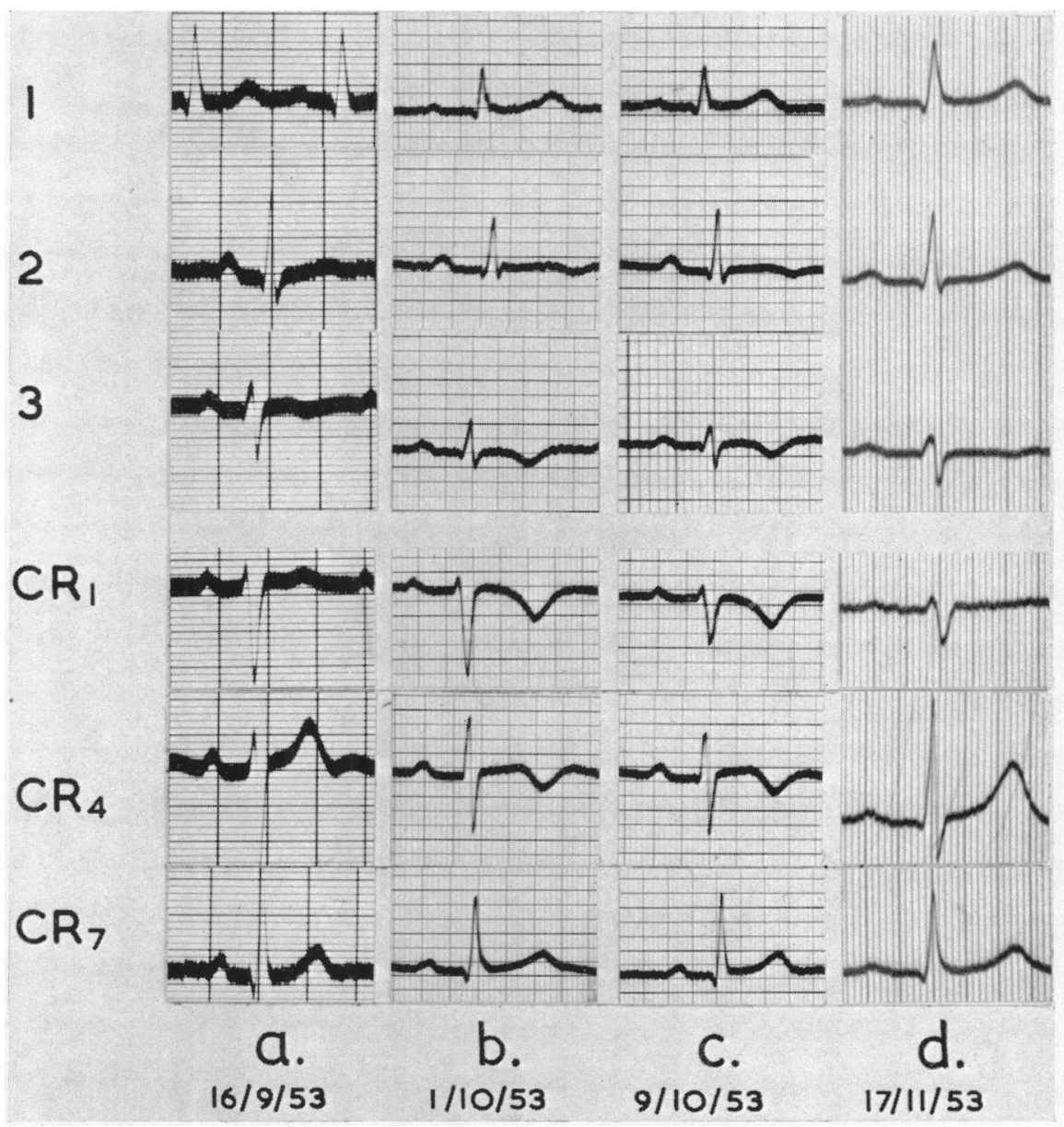

FIG. 3.- Case 4. (a). Taken on first attendance, shows flat T2 but otherwise normal tracing. (b) and (c) Characteristic $T$ wave inversion. In (d) the only possible abnormality. is flat $T$ in CR1. (Death occurred three weeks later.) 
Necropsy showed that death was due to recent massive embolism of the pulmonary trunk and both its main branches; there was evidence also of previous pulmonary embolism. The source of these emboli was shown to be the veins of the lower extremities, and the left femoral and iliac veins contained ante-mortem thrombi.

The heart weighed $344 \mathrm{~g}$. and was not hypertrophied. A small infarct was found in the upper part of the interventricular septum. Macroscopically this infarct was certainly not very recent, but probably at least a month old. Unfortunately no sections were taken from the infarcted area, so that there is no histological evidence of the age of the infarct. There was severe generalized atheroma of both coronary arteries, and the anterior descending branch was particularly severely affected. Several areas of calcification and narrowing were seen, but no actual occlusions of a coronary artery or branch were apparent.

The second patient (Case 5, J. H.) died after twenty-two months of close observation and the electrocardiograms in Fig. 2 were recorded over this period. Necropsy was performed at the London Hospital. The immediate cause of death was infarction of the bowel due to atheromatous occlusion of the superior mesenteric artery at its origin. The heart was removed intact; it weighed $305 \mathrm{~g}$. and was not hypertrophied. The coronary arteries were injected with radio-opaque mass using a modification of the technique described by Schlesinger (1938). The heart was then X-rayed with the results shown in Fig. 4. It is realized that there are theoretical objections to this technique as a means of judging the integrity of the coronary arteries. However, in practice the results appear trustworthy, and in the present case the coronary circulation seemed healthy and there was no evidence of any abnormality in the coronary system.

Subsequent examination confirmed this, for although atheroma was unusually severe and widespread throughout the body, the coronary arteries had been spared in a remarkable fashion and were described as "virtually free of atheroma".

There were two or three bluish-white streaks about $1 \mathrm{~cm}$. long in the posterior wall of the left ventricle
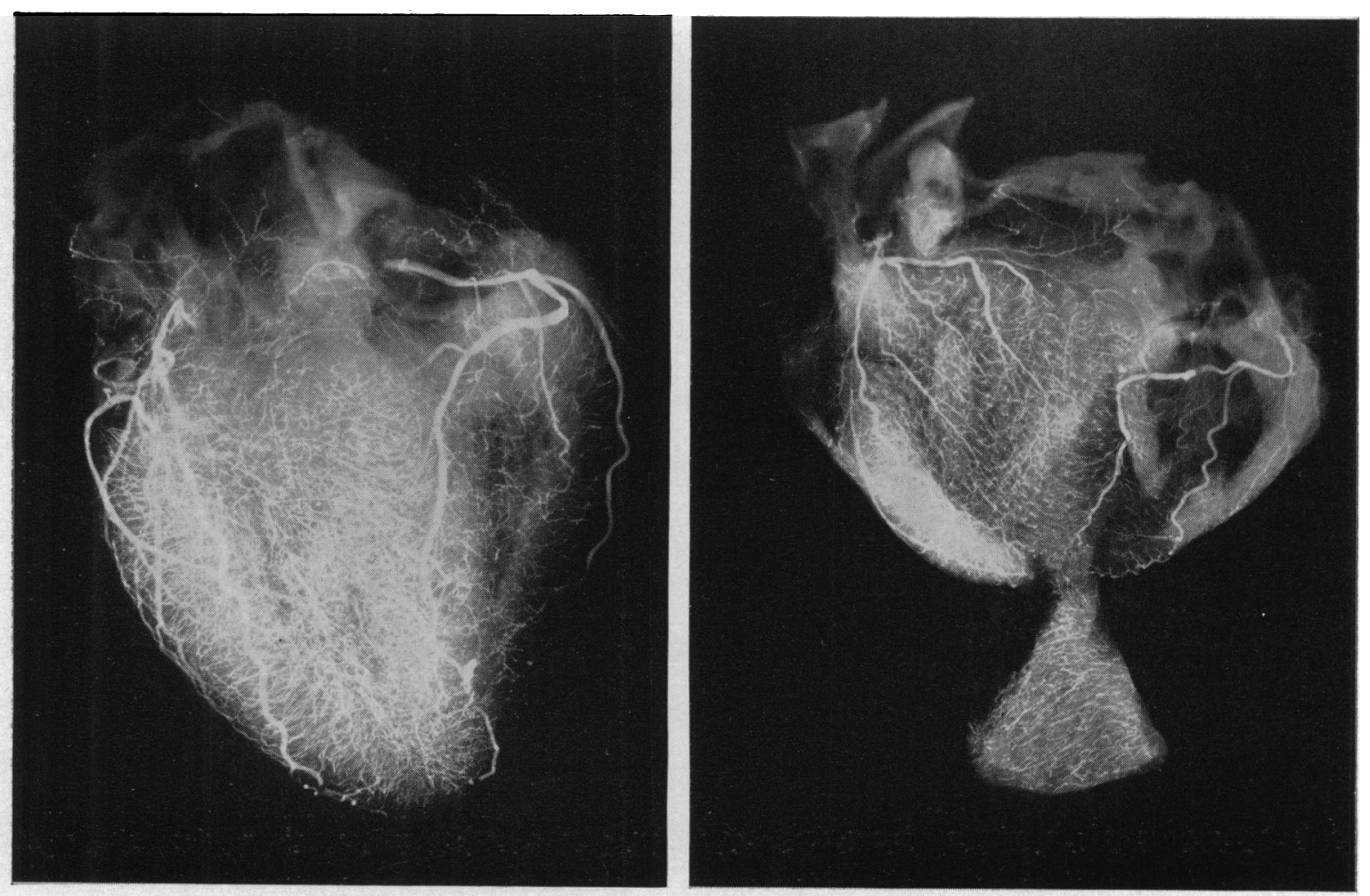

Fig. 4.-Case 5. X-ray photographs of the heart injected with radio-opaque mass. No obvious block is demonstrated in the coronary circulation. 
near the apex, which extended into the interventricular septum. Apart from these, no macroscopic abnormality was detected in the heart. A photomicrograph from a section of the affected area is shown in Fig. 5.

A full histological report by Professor Dorothy Russell is given below.

"A section of the posterior wall of the left ventricle at the junction with the interventricular septum and right ventricle. The myocardium is occupied by fibrosis extending over an area measuring $1.5 \mathrm{~cm}$. The fibrosis is reticulated to include irregular groups of muscle-fibres, many of which are hypertrophied. The collagen of the fibrosis is dense, and evidently of considerable age. There is no evidence of inflammation nor of progression of the fibrosis. None of the regional arteries suggests previous occlusion. The remainder of the myocardium appears healthy, apart from the presence of lipo-fuchsin granules in the cytoplasm of the fibres. The changes found, therefore, are indistinguishable from those of an old infarct."

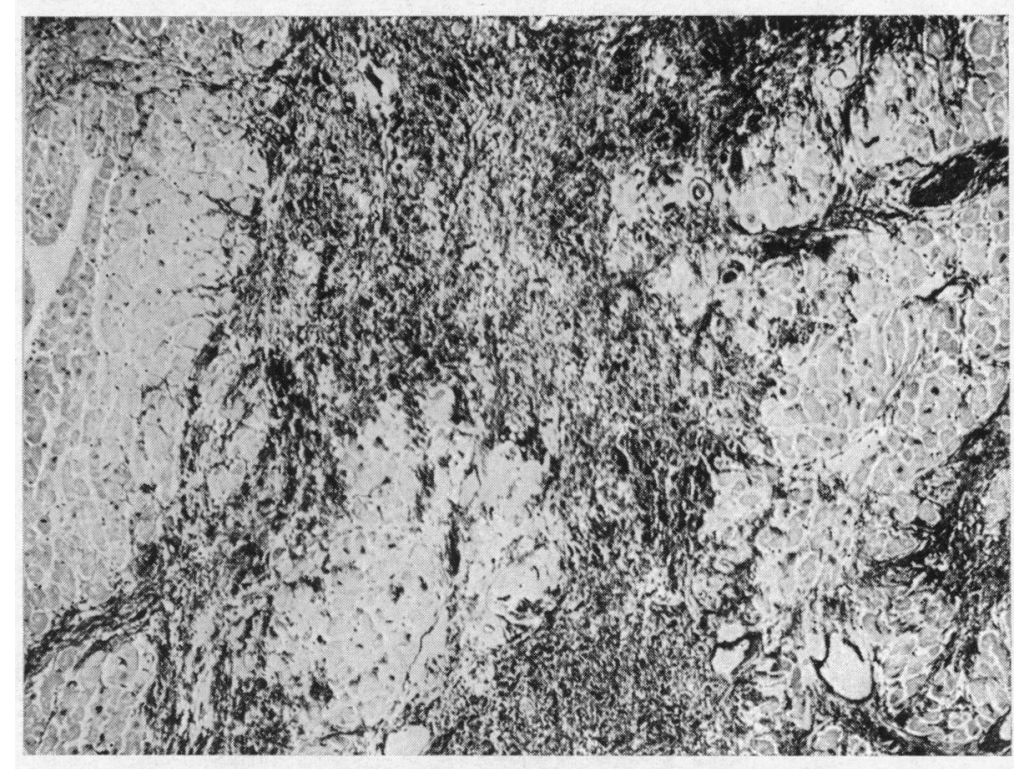

Fig. 5.-Case 5. Photomicrograph $(\times 62)$ of the area of fibrosis found at autopsy. Remnants of the injection "mass" can be seen in the arterioles which otherwise appear normal.

\section{DisCUSSION}

Evidence of cardiac infarction was thus found at necropsy in both fatal cases. The close similarity of the electrocardiograms, not only in the initial abnormalities but also in their subsequent behaviour, makes it probable that cardiac infarction had also occurred in the three patients who still survive. Accordingly this assumption will form the basis of the discussion that follows.

It has been mentioned that previous authors ascribed this type of electrocardiographic pattern to myocardial ischæmia. This is not in keeping with the usual description of the " ischæmic" tracing, the most important and consistent characteristic of which is depression of the S-T segment. Furthermore the diagnosis of cardiac ischæmia by the effort test frequently depends entirely upon the production of this feature. Yet in the present series significant S-T segment depression never occurred-an apparent discrepancy that requires explanation.

The term " ischæmia " implies that a living tissue is receiving an inadequate blood supply which is detrimental to the metabolism and function of that tissue. In the case of the heart, the clinical manifestation of this is ischæmic pain in the chest, or angina pectoris. Dead tissue cannot properly be considered to be ischæmic, since it performs no function and requires no supply of blood. Hence an electrode placed over an area of dead muscle will show changes of infarction and not of ischæmia. 
Accepting, therefore, that cardiac infarction occurred in all the present series, there is no reason to postulate the presence of ischæmia and the apparent anomaly of the iso-electric S-T segment vanishes.

It is known that the production of a pathological $\mathrm{Q}$ wave depends upon the extent of muscle necrosis and hence upon the size of the area of infarction. Both infarcts revealed at autopsy were small and it is not surprising that they were not large enough to cause pathological Q waves. That they were in the interventricular septum in both instances fitted well with the electrocardiographic signs, for it was the præcordial leads, taken from the region of the septum, that showed the most consistent and striking changes. The extent to which these small infarcts encroach upon the anterior or posterior surfaces of the ventricle is presumably the factor that determines which particular limb lead will show $\mathbf{T}$ wave changes, when these occur.

There remains the question of the return to normal of the electrocardiograms. Remarkably little has been written on this important subject and most standard works on the heart do not even consider the possibility of such complete recovery after cardiac infarction. A possible explanation is that anastomotic channels develop which restrict the spread of the infarct, limit its extent, and allow the process of fibrosis and contraction of the scar to proceed unimpeded. Blumgart et al. (1940) demonstrated the existence of inter-coronary anastomoses, and Laubry et al. (1948) showed that the interventricular septum was rich in these anastomoses, which were particularly large and numerous after cardiac infarction. These findings were corroborated by Zoll et al. (1952). It would thus seem that circumstances are peculiarly favourable for the healing of small septal infarcts and for electrocardiographic recovery.

It has been shown that these electrocardiographic changes, which signify septal infarction, may persist for several weeks unchanged and subsequently improve quite quickly. Whether this static period of a month or so represents the time necessary for anastomotic channels in the septum to develop is unknown.

Although myocardial infarction usually results from coronary occlusion, it has long been recognized that post-mortem examination may demonstrate obvious cardiac infarction, yet fail to show any occlusion of the coronary arteries. Friedberg and Horn (1939) reported thirty-seven such cases and their findings were supported by Ravin and Geever (1946). Wang et al. (1948) were unable to demonstrate coronary occlusion in 39 per cent of all cases of myocardial infarction found at necropsy in a twenty-year period at the Massachusetts General Hospital. All these authors emphasized that in most instances severe disease of the coronary arteries was present with areas of coronary narrowing, and postulated that infarction of the heart resulted from prolonged anoxæmia as the result of inadequate coronary circulation. It was further suggested that hypertrophy of the myocardium from any cause, particularly systemic hypertension, would exaggerate the relative poverty of the coronary circulation so that any sudden "stress" such as exertion, tachycardia, humoral factors, or severe anæmia, might be sufficient to cause acute myocardial damage, although the coronary arteries remained patent. The corresponding clinical syndrome was termed " coronary insufficiency" by Master (1946) and " coronary failure " by Freedberg et al. (1948).

Of the two autopsies discussed in this paper, the first (Case 4) can evidently be placed in this category; no obvious coronary occlusion was found, but the coronary arteries were extensively diseased and a small myocardial infarct was seen. In the second autopsy (Case 5) cardiac infarction was associated with apparently normal coronary arteries. Although such findings are rare, they are by no means unknown; thus Lisa and Ring (1932) found normal coronary arteries at autopsy in seven instances in a series of one hundred myocardial infarctions, and Gross and Sternberg (1939) further reported fifteen examples of extensive myocardial infarction without significant disease of the coronary arteries. It is in such cases that the possibility of coronary arteriospasm merits serious consideration, for the absence of structural changes in the coronary vessels at necropsy leaves no satisfactory alternative explanation for myocardial infarction.

For many years clinicians have suggested that stimuli originating outside the heart might cause reflex spasm of the coronary arteries resulting in myocardial ischæmia, angina pectoris, and even cardiac infarction. In many earlier studies reported the gall bladder, stomach, and colon have been 
the principal organs incriminated. Most of the evidence adduced to support this theory rests on the similarity in the type and distribution of the pain experienced by individual patients. It has been reported that changes in the electrocardiogram indicative of myocardial disease may disappear following the removal of gall stones (Fitzhugh and Wolferth, 1935; Miller 1942; Clarke, 1945). Most experienced physicians have witnessed the abolition of apparent angina pectoris in isolated cases by cholecystectomy. The association of hiatus hernia with chest pain and even electrocardiographic changes is well known, whilst the difficulty of distinguishing certain types of " heart burn " from cardiac pain needs no emphasis. Dworken et al. (1952) have recently shown that distension of the splenic flexure with a balloon in susceptible patients may cause substernal pain "very like" angina pectoris. In all these extra-cardiac syndromes it is frequently impossible to exclude the co-existence of coronary artery disease.

Of the present series of patients, three suffered from demonstrable organic disease in the digestive tract in addition to cardiac infarction; however, there is no objective evidence that this was other than a casual relationship. In one instance (Case 3) infarction occurred after cholecystectomy; in another (Case 5) the electrocardiogram remained normal at the time when his peptic ulcer symptoms were most severe, and thus presumably when reflex coronary arteriospasm might be expected. Although the occurrence of cardiac infarction in this patient remains unexplained, there is no direct evidence that reflex arteriospasm played any part.

It has been stated that the prognosis in patients presenting this reversible electrocardiographic pattern is good. East and Oram (1948) remarked that opportunities for necropsy were few and that the only post-mortem examination of their series revealed not heart disease but an obscure septicæmia; two areas of fibrosis were found in the anterior wall of the left ventricle near the apex, but the coronary arteries were stated to be perfectly healthy: these findings are very similar to those in the second necropsy reported in this paper (Case 5). Evans (1955) had no deaths in his series. Holzman (1955), who described similar electrocardiograms under the heading of " rudimentary anterior wall infarction ", wrote that " due to the good prognosis of the syndrome, personal post-mortem findings are lacking ". Obviously this universal paucity of pathological evidence has been a major factor in delaying the recognition of permanent structural cardiac damage in these cases and serves to emphasize that this damage is slight.

The state of the coronary arteries must, however, influence the prognosis. Although heart disease was not the direct cause of death in either of the two fatal cases in this series, in one (Case 4) severe coronary artery disease was found. The fact that most authors report a good prognosis indicates that this must be unusual. Nevertheless it would be of value if evidence of coronary artery disease could be obtained during life. Once the electrocardiogram has become normal the only objective means of assessing the functional state of the coronary arteries is by carrying out an exercise test, recording the electrocardiograms before and after exertion. Experience with this test shows that it may yield valuable information, but it is well recognized that the procedure can be dangerous. For this reason one patient (Case 3), an elderly woman with hypertensive heart disease, was not subjected to the test; another (Case 4) died before the test could be performed, and a third (Case 5) was unable to cooperate owing to severe claudication.

Effort tests were performed on the two remaining patients; one test was positive (Case 1) and the other negative (Case 2). In neither instance was cardiac pain produced, although the exertion was severe. Both patients are alive, and it is inferred that functionally significant coronary artery disease exists in the first patient but not in the second. Prognosis must be guided by these findings.

The cases reported in this paper show that the electrocardiogram can return to normal after localized infarction of the interventricular septum has occurred. Information concerning the incidence of this type of case would be extremely valuable. Of the present series all were referred to the Medical Unit Out-Patient Clinic, one of six general medical "firms" in a hospital that also maintains a large cardiac department. They were all seen for the first time between May 1952 and March 1954-a span of twenty-two months. It would thus seem that this type of " restricted" infarction may not be particularly rare in non-specialized clinics and although the actual incidence is 
impossible to assess, the fact that the symptoms may not immediately suggest heart disease lends support to this view and possibly explains why these patients were not referred to a cardiologist in the first instance.

\section{SUMMARY AND CONCLUSIONS}

Five patients are reported in whom chest pain was accompanied by an abnormal electrocardiogram of a distinctive pattern which always reverted to normal. The characteristics of this pattern are described, and it is suggested that the subsequent behaviour of the electrocardiogram may be predicted.

From the findings at necropsy in two patients who died, it is concluded that this electrocardiogram is the result of localized infarction of the interventricular septum. The subsequent recovery of the electrocardiogram is discussed and is believed to be due to the development of intercoronary anastomoses in the septum.

The prognosis in this group of patients is generally good, but depends upon the extent of coronary artery disease in the individual case. It is suggested that the effort electrocardiogram may give useful information in this respect.

Reasons are advanced for the belief that this "syndrome" may not be particularly uncommon in general medical practice.

All these patients were in the care of Professor Clifford Wilson; it is a pleasure to express my gratitude for his permission to study these patients, and for his encouragement and advice in the preparation of this paper. I wish to thank Professor Dorothy Russell for the histological report on Case 5 and Dr. C. Raeburn for the necropsy findings in Case 4. The majority of the electrocardiograms were recorded in the Cardiac Department, London Hospital, and are available for reproduction by courtesy of Dr. William Evans. My thanks are also due to Sir John Parkinson and Dr. William Evans for much helpful criticism.

\section{REFERENCES}

Blumgart, H. L., Schlesinger, M. S., and Davis D. (1940). Amer. Heart J., 19, 1.

Clarke, N. E. (1945). Amer. Heart J., 29, 628.

Dworken, H. J., Biel, F. J., and Machella, T. E. (1952). Gastroenterology, 34, 222.

East, T., and Oram, S. (1948). Brit. Heart J., 10, 263.

Evans, W. (1955). Brit. Heart J., 17, 15.

Fitzhugh, T., and Wolferth, C. C. (1935). Ann. Surg., 101, 478.

Freedberg, A. S., Blumgart, M. L., Zoll, P. M., and Schlesinger, M. J. (1948). J. Amer. med Ass., $138,107$.

Friedberg, C. K., and Horn, H. (1939). J. Amer. med. Ass., 112, 1675.

Gross, M., and Sternberg, W. H. (1939). Arch. intern. Med., 64, 249.

Holzman, M. (1955). Amer. Heart J., 50, 407.

Laubry, C. H., Soulié, P., and Thys, H. (1948). Arch. Mal. Caur., 41, 1.

Lisa, J. R., and Ring, A. (1932). Arch. intern. Med., 50, 131.

Master, A. M. (1946). New York Med., 2, No. 9, 19.

Miller, H. R. (1942). Amer. Heart J., 24, 579.

Ravin, A., and Geever, E. F. (1946). Arch. intern. Med., 78, 125.

Schlesinger, M. J. (1938). Amer. Heart J., 15, 528.

Wang, C. H., Bland, E. F., and White, P. D. (1948). Ann. intern. Med., 29, 601.

Zoll, P. M., and Norman, L. R. (1952). Circulation, 6, 832. 